\title{
TRENDS IN LIFE SATISFACTION AND SELF-RATED HEALTH IN CZECH SCHOOL-AGED CHILDREN: HBSC STUDY
}

\author{
Lenka Hodačová1, Eva Hlaváčková2, Dagmar Sigmundová3, Michal Kalman³ ${ }^{3}$ Jaroslava Kopčáková4, 5 \\ 'Department of Social Medicine, Faculty of Medicine in Hradec Králové, Charles University, Hradec Králové, Czech Republic \\ ${ }^{2}$ Department of Clinical Subspecialities, Faculty of Health Studies, University of Pardubice, Pardubice, Czech Republic \\ ${ }^{3}$ Insitute of Active Lifestyle, Faculty of Physical Culture, Palacký University Olomouc, Olomouc, Czech Republic \\ ${ }^{4}$ Department of Health Psychology, Faculty of Medicine, Pavol Jozef Šafárik University in Košice, Košice, Slovak Republic \\ ${ }^{5}$ Graduate School, Kosice Institute for Society and Health, Pavol Jozef Šafárik University in Košice, Košice, Slovak Republic
}

\section{SUMMARY}

Objective: The aim of the study is to examine cross-sectional time trends of life satisfaction and self-rated health in a representative sample of Czech children aged 11, 13 and 15 years using the Health Behaviour in School-aged Children (HBSC) study data from the Czech Republic.

Methods: Data from survey years 2002, 2006, 2010 and 2014 was used. The sample consisted of 16,357 participants (48.5\% of boys). Life satisfaction (LS) was measured by Cantril's ladder; self-rated health was measured through the simple item "Would you say your health is: excellent, good, fair, poor".

Results: Most of the children were satisfied with their lives in all surveyed years (mean LS scores range from 7.21 to 7.51 ; maximum 10). LS was consistently significantly associated $(p<0.001)$ with age and gender. Overall, children and adolescents in the Czech Republic also reported good health. In total, $87.6 \%$ of respondents from all samples reported their health as excellent or good. Gender was found to be significantly associated with self-rated health $(p<0.05)$ in all surveyed years.

Conclusions: No permanent trends in both followed indicators have been seen in the examined period.

Key words: HBSC study, adolescents, life satisfaction, self-rated health, time trends

Address for correspondence: L. Hodačová, Charles University, Faculty of Medicine in Hradec Králové, Department of Social Medicine, Šimkova 870, 50003 Hradec Králové, Czech Republic. E-mail: hodacoval@lfhk.cuni.cz

https://doi.org/10.21101/cejph.a4820

\section{INTRODUCTION}

Life satisfaction (LS) is defined as cognitive global judgement of one's life. It is an important component of subjective well-being, a multifactorial psychological concept consisting of emotional responses (i.e. positive and negative effect), domain satisfaction (e.g. relationship satisfaction, work satisfaction) and cognitive judgement of satisfaction with life as a whole $(1,2)$. LS is relatively stable over time in comparison with subjective feelings relating to the moment (1). It is a useful and simple indicator that provides immediate and understandable benchmark for people responsible for young people's health programmes.

Measures of LS range from multi-item scales to single questions aimed at assessing global LS (3). One of the options is the measurement of LS by Cantril's ladder (4). This is an efficient global measure of high construct validity across socio-demographic factors such as gender, age, marital status, income, employment, and religion (5).

LS is associated both with physical and mental health in children and adolescents as well as with the various health behaviours among them (5-9). Studies have also demonstrated that LS is related to age, gender, material and housing circumstances, family and school environment, and socioeconomic status (6-13). Furthermore, LS in adolescents is strongly influenced by life experiences, social relationships, stress and anxiety, social competence and good coping skills, self-esteem, self-acceptance, the ability to love oneself, optimism, and individual spirituality $(7,8,14$, 15). Low LS can predict the onset of depression and is thought to be associated with a range of psychological and social problems (16). It is also associated with all-cause mortality, suicide and fatal accidents $(17,18)$.

Health is considered an important component of human life. Being in good health enables adolescents to cope with demands of this difficult period and facilitates their transition to adulthood (8). Health can be measured on the basis of objective or subjective health indicators. Within the last few decades we can see a paradigm shift from assessing health and medical outcomes only by somatic indicators and there is an increasing interest being placed on measurements of perceived health status $(18,19)$.

Thus, subjective assessment has become increasingly important in research as well as in clinical settings. Self-rated health (SRH) represents a meaningful, subjective indicator for general health. It is a multifactorial composite based on the individual appraisal of one's health that includes an overall sense of function- 
ing, physical, mental and social dimensions of health $(5-7,20)$. It mostly depends on the conscious and unconscious comparison of oneself with peers of the same age (7). SRH is found to be a relatively stable over repeated observations during adolescence $(21,22)$. It deteriorates with disability, health-compromising behaviour and a lack of general well-being (22).

$\mathrm{SRH}$ is an easily accessible indicator of overall health status that can predict objectively measurable health-related outcomes (8). Among adults, SRH is a powerful predictor of future morbidity, mortality, and health service attendance and is also linked to the sick leave from work $(23,24)$. Association between SRH in adolescents and objective health status in adulthood was also detected $(23,25)$. The World Health Organization considers SRH a more appropriate measure of adolescent health than traditional morbidity and mortality measures (26).

Adolescents' SRH was found to be associated with age, gender, level of education, life satisfaction, lifestyle factors, access to education, health and social services, socioeconomic status $(7,8$ $11,13,27)$. Besides the above mentioned factors, SRH is closely linked to anxiety and depression (14). It is also influenced by family structure, communication with parents, school environment, success, failure, or bullying $(8,28)$.

LS as well as SRH are seen to be important components of broader strategies oriented to improve health and overall quality of life for children and young people (29).

The objective of the present study was to examine crosssectional time trends of LS and SRH in a representative sample of Czech children using the Health Behaviour in School-aged Children study (HBSC) data from the Czech Republic. This study can serve as an important source of information about youth generation and brings powerful data and insight into their perception of health and life.

\section{MATERIALS AND METHODS}

Data for our work was drawn from the Czech part of the international HBSC study. This is a major cross-sectional study that deals with monitoring of health, life satisfaction and lifestyle determinants of the adolescent population of school-aged children. HBSC has been conducted at four-year intervals since 1983/1984 in a growing number of countries. Its methodology is based on the WHO recommendations and all countries follow the same research protocol in terms of sampling, questionnaire items and survey administration $(7,8$, 11, 30). The Czech Republic has been participating since 1994.
The aims, methods and design of the study has been described elsewhere in detail $(7,26,31)$.

For this paper, data from survey years 2002, 2006, 2010 and 2014 was used because these included items concerning LS and SRH. Data was collected by means of a standardized questionnaire from a representative sample of Czech children aged 11, 13 and 15 years. All children voluntarily filled in questionnaires during class hours. The study was conducted in accordance with ethical standards. Children response rates were $>70 \%$ in all years. There were 19,726 participants in the total data set, but 3,369 were excluded because they were younger or older than the targeted age group $(11,13,15$ years) or there were missing data on age or sex. Hence, the final sample for analyses consisted of 16,357 participants ( $48.5 \%$ of boys).

The paper examines overall LS and the general health perception - SRH. LS was measured by the so called Cantril's ladder (4), an efficient, global measure with high construct validity (5, 33). Young people were presented a picture of a ladder with steps ranging from 0 to 10 (where 10 represented the best possible life and 0 the worst). They were asked to indicate where on the ladder they would place their life at present. A score 6 or more indicated high life satisfaction $(6,7)$.

SRH was assessed by asking children: "Would you say your health is...?" and four-point response scale was used including the categories: excellent, good, fair, and poor. SRH is a standardised indicator that has been used considerably in various health research. For the current analysis, answers were dichotomised into excellent/good versus fair/poor.

Statistical data analyses were performed in the program IBM SPSS v. 22. Methods of descriptive statistics, ANOVA and LSD post hoc test for assessment of LS as continuous variable were used. Differences in proportion of positive SRH and high LS among boys and girls were evaluated using Chi-square test. Trends in positive SRH (excellent and good) and high LS (a score 6 or more) were evaluated using logistic regression (Enter method) analysis. OR (odds ratio) with independent categorical variable study year was calculated, with $95 \%$ confidence interval $(95 \% \mathrm{CI})$.

\section{RESULTS}

The majority of Czech children were satisfied with their lives. Using the Cantril's ladder (scale 0-10), most children (82.5\%) reported values higher than two thirds of the possible maximum score. The mean value for LS among all of the sample subjects

Table 1. Sample characteristics $(N=16,357)$

\begin{tabular}{|l|c|c|c|c|}
\hline \multirow{2}{*}{ Variables } & \multicolumn{4}{|c|}{ Year of survey } \\
\cline { 2 - 5 } & $\mathbf{2 0 0 2}$ & $\mathbf{2 0 0 6}$ & $\mathbf{2 0 1 0}$ & $\mathbf{2 0 1 4}$ \\
\cline { 2 - 5 } & $\mathrm{n}=\mathbf{4 , 0 3 9}$ & $\mathrm{n}=\mathbf{4 , 1 0 5}$ & $\mathrm{n}=\mathbf{3 , 8 3 0}$ & $\mathrm{n}=\mathbf{4 , 3 8 3}$ \\
\hline Boys & $\mathbf{4 7 . 2 \%}$ & $50.4 \%$ & $47.4 \%$ & $48.7 \%$ \\
\hline Girls & $52.8 \%$ & $49.6 \%$ & $52.6 \%$ & $51.3 \%$ \\
\hline 11 years & $33.9 \%$ & $31.6 \%$ & $31.9 \%$ & $31.1 \%$ \\
\hline 13 years & $32.9 \%$ & $33.8 \%$ & $33.2 \%$ & $34.1 \%$ \\
\hline 15 years & $33.2 \%$ & $34.6 \%$ & $34.9 \%$ & $34.8 \%$ \\
\hline
\end{tabular}


was $7.36(\mathrm{SD}=1.90)$. In terms of separate surveys carried out in 2002, 2006, 2010 and 2014, mean LS scores range from 7.21 (in 2014) to 7.51 (in 2010). Differences for mean LS scores between the years 2002, 2006 and 2014 were significant at $p<0.001$, between 2006 and 2010 at $p<0.05$. No statistical differences were found between 2002 and 2014.

For boys, mean values for LS ranged from 7.29 to 7.64 in individual surveyed years. A significant increase in 2010 and decrease in 2014 was recorded compared to 2002 and 2006. For girls, LS scores ranged from 7.13 to 7.41. Compared to 2002, a statistically significant decrease was recorded in 2006 and 2010; a significant increase was also observed in 2010 compared to 2006. Differences were significant at $\mathrm{p}<0.05$.

Trends in LS by age and gender from 2002 to 2014 are presented in Figure 1. For boys, mean values for LS ranged from

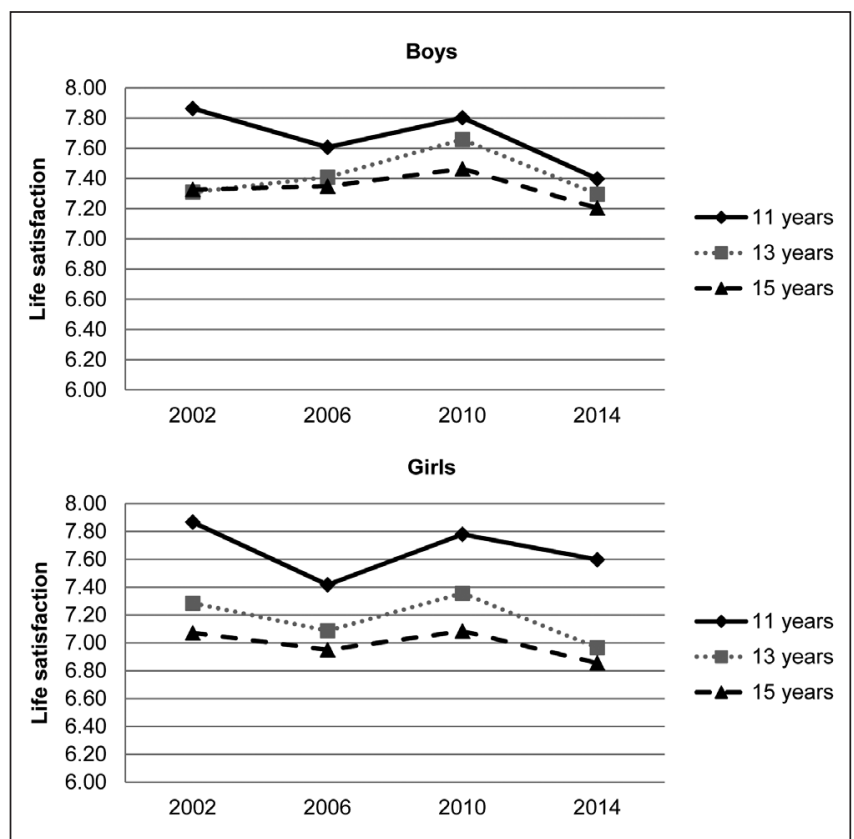

Fig. 1. Trends in life satisfaction by age and gender during 2002 and 2014.
7.86 (11-year-boys, in 2002) to 7.20 (15-year-boys, in 2014). For girls, mean values ranged from 7.87 (11-year-girls, in 2002) to 6.86 (15-year-girls, in 2014). The results consistently show that there are significant gender differences in LS, with boys reporting higher LS in all surveyed years $(\mathrm{p}<0.001$ in 2006; $\mathrm{p}<0.001$ in $2010 ; p<0.01$ in 2014) apart from 2002. LS was also significantly associated with age $(\mathrm{p}<0.001)$. The highest LS was consistently observed in 11-year old children and the lowest scores were recorded for young people aged 15 .

High LS (score 6 or more) by age and gender in the surveyed years and comparison based on findings from logistic regression analyses are presented in Table 1 . From $81.3 \%$ to $87.7 \%$ of boys in all age categories reported high LS. Compared to 2002, the significant increase was observed only in 13-year-olds $(\mathrm{OR}=1.42$ $(95 \%$ CI $1.02-1.97) ; p<0.05)$ in 2010 . Around $80 \%$ of the girls viewed their LS as high (the percentage ranged from 76.0 to 86.4). Compared to 2002, significant decrease was found only for 11 -year-olds in $2006(\mathrm{OR}=0.57(95 \%$ CI $0.43-0.76) ; \mathrm{p}<0.001)$ and in $2014(\mathrm{OR}=0.75(95 \% \mathrm{CI} 0.56-0.99) ; \mathrm{p}<0.05)$.

In total, $87.6 \%$ of respondents from all samples reported their health as excellent or good. For boys, SRH as excellent/good was reported by $89.8 \%$ in 2002 , by $90.3 \%$ in 2006 , by $91.7 \%$ in 2010 , and by $87.0 \%$ in 2014 . For girls, $87.3 \%$ reported excellent/ good health in $2002,85.7 \%$ in $2006,89.3 \%$ in 2010 , and $81.1 \%$ in 2014 reported their health as excellent or good. Differences between gender were statistically significant at $\mathrm{p}<0.05$ for all surveyed years. In terms of age groups, significant association was found only between 11-year-olds and 15-year-olds in 2014 $(\mathrm{p}<0.01)$.

SRH in excellent/good categories by age groups for boys and girls from 2002 to 2014 is presented in Table 2. In all surveyed years, the percentage of boys that rated their health as excellent or good ranged from $85.4 \%$ to $92.5 \%$. Compared to 2002 , a statistically significant decrease was observed only in 15-year-olds $(\mathrm{OR}=0.62(95 \% \mathrm{CI} 0.45-0.86) ; \mathrm{p}<0.01)$, in the survey from 2014 . The percentage of girls assessing their health as excellent/good ranged from $79.3 \%$ to $89.9 \%$. Nevertheless, a significant decrease compared to the survey from 2002 was observed only in 2014 in all age categories: in 11-year-olds $\mathrm{OR}=0.72(95 \% \mathrm{CI} 0.53-0.98)$;

Table 2. High life satisfaction score by age and gender from 2002 to 2014

\begin{tabular}{|c|c|c|c|c|c|c|c|c|c|c|c|c|c|}
\hline \multirow{4}{*}{ Variable } & \multirow{4}{*}{$\begin{array}{c}2002 \\
\% \\
\end{array}$} & \multirow{4}{*}{$\begin{array}{c}2006 \\
\% \\
\end{array}$} & \multirow{4}{*}{$\begin{array}{c}2010 \\
\% \\
\end{array}$} & \multirow{4}{*}{$\begin{array}{c}2014 \\
\% \\
\end{array}$} & \multicolumn{3}{|c|}{2006 vs. 2002} & \multicolumn{3}{|c|}{2010 vs. 2002} & \multicolumn{3}{|c|}{2014 vs. 2002} \\
\hline & & & & & \multirow{3}{*}{ OR } & \multicolumn{2}{|c|}{$\mathrm{Cl}$} & \multirow{3}{*}{ OR } & \multicolumn{2}{|c|}{$\mathrm{Cl}$} & \multirow{3}{*}{ OR } & \multicolumn{2}{|c|}{$\mathrm{Cl}$} \\
\hline & & & & & & \multirow{2}{*}{ Lower } & \multirow{2}{*}{ Upper } & & \multirow{2}{*}{ Lower } & \multirow{2}{*}{ Upper } & & \multirow{2}{*}{ Lower } & \multirow{2}{*}{ Upper } \\
\hline & & & & & & & & & & & & & \\
\hline \multicolumn{14}{|l|}{ Boys } \\
\hline 11 years & 85.0 & 83.0 & 87.5 & 81.3 & 0.86 & 0.64 & 1.16 & 1.23 & 0.89 & 1.70 & 0.76 & 0.57 & 1.02 \\
\hline 13 years & 83.4 & 85.9 & 87.7 & 82.3 & 1.20 & 0.89 & 1.63 & $1.42^{*}$ & 1.02 & 1.97 & 0.92 & 0.69 & 1.23 \\
\hline 15 years & 85.8 & 85.9 & 87.6 & 82.5 & 1.01 & 0.74 & 1.36 & 1.16 & 0.84 & 1.61 & 0.77 & 0.58 & 1.04 \\
\hline \multicolumn{14}{|l|}{ Girls } \\
\hline 11 years & 86.4 & 78.4 & 85.5 & 82.7 & $0.57^{* * *}$ & 0.43 & 0.76 & 0.93 & 0.68 & 1.26 & $0.75^{*}$ & 0.56 & 0.99 \\
\hline 13 years & 80.1 & 77.1 & 82.5 & 76.9 & 0.84 & 0.65 & 1.08 & 1.17 & 0.90 & 1.53 & 0.83 & 0.65 & 1.06 \\
\hline 15 years & 80.1 & 78.6 & 80.4 & 76.0 & 0.91 & 0.70 & 1.18 & 1.02 & 0.78 & 1.32 & 0.79 & 0.61 & 1.01 \\
\hline
\end{tabular}

Results from logistic regression; \% percentage of participants who reported positive life satisfaction; OR: odds ratio (cohort from year 2002 is reference group); Cl: $95 \%$ confidence interval; ${ }^{*} p<0.05,{ }^{* *} p<0.01,{ }^{* * *} p<0.001$. 
Table 3. Self-rated health in excellent and good categories by age and gender from 2002 to 2014

\begin{tabular}{|c|c|c|c|c|c|c|c|c|c|c|c|c|c|}
\hline \multirow{3}{*}{ Variable } & \multirow{3}{*}{$\begin{array}{c}2002 \\
\%\end{array}$} & \multirow{3}{*}{$\begin{array}{c}2006 \\
\%\end{array}$} & \multirow{3}{*}{$\begin{array}{c}2010 \\
\%\end{array}$} & \multirow{3}{*}{$\begin{array}{c}2014 \\
\%\end{array}$} & \multicolumn{3}{|c|}{2006 vs. 2002} & \multicolumn{3}{|c|}{2010 vs. 2002} & \multicolumn{3}{|c|}{2014 vs. 2002} \\
\hline & & & & & \multirow{2}{*}{ OR } & \multicolumn{2}{|c|}{$\mathrm{Cl}$} & \multirow{2}{*}{$\mathrm{OR}$} & \multicolumn{2}{|c|}{$\mathrm{Cl}$} & \multirow{2}{*}{$\mathrm{OR}$} & \multicolumn{2}{|c|}{$\mathrm{Cl}$} \\
\hline & & & & & & Lower & Upper & & Lower & Upper & & Lower & Upper \\
\hline \multicolumn{14}{|l|}{ Boys } \\
\hline 11 years & 90.4 & 89.8 & 92.5 & 87.9 & 0.93 & 0.65 & 1.34 & 1.30 & 0.87 & 1.94 & 0.77 & 0.54 & 1.09 \\
\hline 13 years & 88.4 & 91.5 & 91.0 & 87.7 & 1.42 & 0.99 & 2.04 & 1.33 & 0.91 & 1.94 & 0.94 & 0.67 & 1.31 \\
\hline 15 years & 90.4 & 89.7 & 91.7 & 85.4 & 0.92 & 0.65 & 1.32 & 1.17 & 0.79 & 1.71 & $0.62^{* *}$ & 0.45 & 0.86 \\
\hline \multicolumn{14}{|l|}{ Girls } \\
\hline 11 years & 88.0 & 86.9 & 89.9 & 84.1 & 0.91 & 0.66 & 1.25 & 1.22 & 0.86 & 1.73 & $0.72^{*}$ & 0.53 & 0.98 \\
\hline 13 years & 87.8 & 85.8 & 90.8 & 80.2 & 0.84 & 0.61 & 1.14 & 1.37 & 0.98 & 1.93 & $0.56^{* * *}$ & 0.42 & 0.75 \\
\hline 15 years & 86.2 & 84.6 & 87.3 & 79.3 & 0.88 & 0.65 & 1.18 & 1.10 & 0.81 & 1.50 & $0.61^{* * *}$ & 0.47 & 0.81 \\
\hline
\end{tabular}

Results from logistic regression; \% percentage of participants who reported positive health; OR: odds ratio (cohort from year 2002 is the reference group); Cl: $95 \%$ confidence interval; ${ }^{*} p<0.05,{ }^{* *} p<0.01,{ }^{* * *} p<0.001$.

$\mathrm{p}<0.05$, in 13-year-olds OR $=0.56(95 \%$ CI $0.42-0.75) ; \mathrm{p}<0.001$ and in 15-year-olds OR $=0.61(95 \%$ CI $0.47-0.81) ; \mathrm{p}<0.001$.

\section{DISCUSSION}

LS and SRH are closely linked and mutually determined. They are considered the essential components of the quality of life and they strongly influence the optimal development in childhood (7, $8,26)$. LS and SRH has become increasingly important. They can be assessed on the basis of various tools but the validity of the results is enhanced by using standardised tools. The HBSC study by using long-term uniform methodology allows to compare the results as well as to monitor the trends $(7,26,32)$.

According to our results, LS of Czech children is high in the long-term. Since 2002, the mean values for life satisfaction as measured using the Cantril's ladder have been permanently higher than 7 and it did not fall below 6 in any of the followed categories. Although some significant differences in LS were observed during the followed period, no permanent rising or descending trends can be seen.

LS was found to be linked with many external and internal factors. As for external factors, satisfaction is enhanced by functional family, supportive teachers, positive attitude to school, and good peer relationships $(7,8,33,34)$. From the internal factors it is temperament, e.g. the level of extroversion or neuroticism (35) and character (36).

LS was significantly related to age and gender of children. Older children and girls consistently reported lower level of LS. These findings are supported by the results from other countries $(7,30,32)$. These differences are perceived as a result of the physical, psychological and social changes experienced in adolescence (hormonal changes, changes in the body, thinking, social relationships, roles, identity search), as well as gender characteristics (boys tend to experience negative emotions less frequently than girls, they cope with their emotions better, their attitudes are less complicated, they are more satisfied with their appearance and are more engaged in physical activities) $(7,8)$.

Comparison of LS among the countries participating in the HBSC study does not seem very optimistic for the Czech Republic. Czech children in all three age categories were placed far below the average values achieved in the HBSC study in 2014. While the 15-year old children were placed 37th among the 42 monitored countries, the categories of 11-year and 13-year old children were placed at the next-to-last position. High LS score was assessed by $90 \%$ and more 11 -year old children in fifteen countries participating in the HBSC study but only by $82 \%$ of Czech children, that is $13 \%$ less compared to Albanian children placed at the first position (8). Slightly better results can be seen in comparison from the years 2010, 2006 and 2002. In these years Czech children in all three age categories were placed around or below the average values in comparison with other countries participating in the HBSC study $(7,30,32)$. Life satisfaction is strongly affected by a number of additional factors. Further detailed analyses are needed to explain why Czech children are placed at the lower position in comparison with other countries. We suppose that qualitative research could also bring important information.

As for SRH, similar relations as for LS were observed. In terms of gender, boys consistently assessed their health as better compared to girls in all surveyed years. Girls tend to complain of various health problems more frequently, which increases with age. There are hardly any significant differences in self-rating health among boys in different age categories $(7,8)$. Based on our results, no statistically significant effect of age on SRH was proved. It is positive that majority of Czech children (nearly 90\%) reported their health as excellent or good. When focusing on long-termtrends in individual age categories, no permanent trends in SRH among Czech children can be seen. Compared to 2002, significant decrease of assessing health as excellent or good was observed in 15-year-old boys and in all age categories for girls in 2014.

In the context of comparison with other countries that participated in the HBSC study, with regard to SRH, the percentage of Czech children assessing their health as fair or poor were higher in all three age categories than the average for the study. In 2014, Czech children were placed in the 7th-19th position with the best position for 15-year-old and worst for 11-year-old (8). Better results can be seen in comparison with previous surveys in 2010, 2006 and 2002, where Czech children were placed in the 29 th -35 th position $(7,8,30)$.

Although certain statistically significant differences in some categories were observed, no permanent trends in both followed 
indicators can be seen. The observed differences thus may not necessarily be significant in practice.

Children and adolescents represent vulnerable group and the evaluation of their health and life satisfaction in the broad social context is very important. Uniform methodology of the HBSC study and long-term data can serve as a powerful source of knowledge about the youth generation's attitude to life, health and society. It is necessary to focus on this age category and lead children to positive and responsible approach to life and health.

\section{CONCLUSSIONS}

Results of our study showed that the majority of Czech children were satisfied with their lives and assessed their health as excellent or good. However, no permanent trends in both followed indicators were found. LS and SRH were significantly associated with gender. Girls consistently assess their life satisfaction and health as worse than boys. Life satisfaction was significantly related to age of children as well. It seems to be important to pay attention to aspects of adolescents' health and also prevention programmes should target youth by highlighting and promoting a healthy lifestyle for adolescent boys and girls in different age groups.

\section{Acknowledgements}

The study was supported by the programme PROGRES Q 40 - 09 and by the Czech Ministry of Education, Youth and Sports (MEYS) under Contract No. LG 14043 and by the Scientific Grant Agency of the Ministry of Education, Science, Research and Sport of the Slovak Republic and the Slovak Academy of Sciences, reg. no. 1/0895/14.

\section{Conflict of Interests}

None declared

\section{REFERENCES}

1. Pavot W, Diener E. Review of the satisfaction with life scale. Psychol Assessment. 1993 Jun;5(2):164-72.

2. Diener E, Lucas RE, Oishi S. Subjective well-being: the science of happiness and life satisfaction. In: Snyder CR, Lopez SL, editors Handbook of positive psychology. Oxford: Oxford University Press; 2002. p. 63-73.

3. Abdel-Khalek AM. Measuring happiness with a single-item scale. Soc Behav Personal. 2006 Feb;34(2):139-50.

4. Cantril H. The pattern of human concern. New Brunswick: Rutgers University Press; 1965.

5. Bjarnason T, Bendtsen P, Arnarsson AM, Borup I, Iannotti RJ, Löfstedt $\mathrm{P}$, et al. Life satisfaction among children in different family structures: a comparative study of 36 western societies. Child Soc. 2012 Jan;26(1):5162.

6. Levin KA, Currie C. Family structure, mother-child communication, father-child communication, and adolescent life satisfaction: a crosssectional multilevel analysis. Health Educ Res. 2010;110(3):152-68.

7. Currie C, Zanotti C, Morgan A, Currie D, de Looze M, Roberts C, et al, editors. Social determinants of health and well-being among young people. Health Behaviour In School-Aged Children (HBSC) study: international report from the 2009/2010 survey. Copenhagen: WHO Regional Office for Europe; 2012.

8. Inchley J, Currie D, Young T, Samdal O, Torsheim T, Augustson L, et al, editors. Growing up unequal: gender and socioeconomic differences in young people's health and well-being. Health Behaviour in School-aged Children (HBSC) study: international report from the 2013/2014 survey. Copenhagen: WHO Regional Office for Europe; 2016.
9. Bradshaw J, Keung A, Rees G, Goswami H. Children's subjective wellbeing: international comparative perspectives. Child Youth Serv Rev. 2011 Apr;33(4):548-56.

10. Brooks FM, Magnusson J, Spencer N, Morgan A. Adolescent multiple risk behaviour: an asset approach to the role of family, school and community. J Public Health (Oxf). 2012 Mar;34 Suppl 1:i48-56.

11. Boniel-Nissim M, Tabak I, Mazur J, Borraccino A, Brooks F, Gommans $\mathrm{R}$, et al. Supportive communication with parents moderates the negative effects of electronic media use on life satisfaction during adolescence. Int J Public Health. 2015 Feb;60(2):189-98.

12. Levin KA, Torsheim T, Vollebergh W, Richter M, Davies CA, Schnohr $\mathrm{CW}$, et al. National income and income inequality, family affluence and life satisfaction among 13 year old boys and girls: a multilevel study in 35 countries. Soc Indic Res. 2011 Nov;104(2):179-94.

13. Moor I, Lampert T, Rathmann K, Kuntz B, Kolip P, Spallek J, et al. Explaining educational inequalities in adolescent life satisfaction: do health behaviour and gender matter? Int J Public Health. 2014 Apr;59(2):309-17.

14. Elgar FJ, Craig W, Trites SJ. Family dinners, communication, and mental health in Canadian adolescents. J Adolesc Health. 2013 Apr;52(4):433-8.

15. Diener E, Ng W, Harter J, Arora R. Wealth and happiness across the world: material prosperity predicts life evaluation, whereas psychosocial prosperity predicts positive feeling. J Pers Soc Psychol. 2010 Jul;99(1):52-61.

16. Park N. The role of subjective well-being in positive youth development. Ann Am Acad Polit Soc Sci. 2004 Jan;591(1):25-39.

17. Koivumaa-Honkanen H, Honkanen R, Koskenvuo M, Viinamäki H, Kaprio J. Life dissatisfaction as a predictor of fatal injury in a 20-year follow-up. Acta Psychiatr Scand. 2002 Jun;105(6):444-50.

18. Helliwell JF. Well-being and social capital: does suicide pose a puzzle? Soc Indic Res. 2007 May;81(3):455-96.

19. Ravens-Sieberer U, Torsheim T, Hetland J, Vollebergh W, Cavallo F, Jericek H, et al; HBSC Positive Health Focus Group. Subjective health, symptom load and quality of life of children and adolescents in Europe. Int J Public Health. 2009 Sep;54 Suppl 2:151-9.

20. Breidablik HJ, Meland E, Holmen TL, Lydersen S. Role of parents in adolescent self-rated health: Norwegian Nord-Trøndelag Health Study. Adolesc Health Med Ther. 2010 Sep 6;1:97-104.

21. Boardman JD. Self-rated health among U.S. adolescents. J Adolesc Health. 2006 Apr;38(4):401-8.

22. Breidablik HJ, Meland E, Lydersen S. Self-rated health during adolescence: stability and predictors of change (Young-HUNT study, Norway). Eur J Public Health. 2009 Jan;19(1):73-8.

23. Ilder EL, Benyamani Y. Self-rated health and mortality: a review of twenty-seven community studies. J Health Soc Behav. 1997 Mar;38(1):21-37.

24. Eriksson HG, von Celsing AS, Wahlström R, Janson L, Zander V, Wallman T. Sickness absence and self-reported health a population-based study of 43,600 individuals in central Sweden. BMC Public Health. 2008 Dec $30 ; 8: 426$.

25. Anson O, Shteingrad J, Paran E. Self-rated health and survival: a sevenyears follow-up. Psychology. 2011 Oct;2(9):987-91.

26. Currie C, Nic Gabhainn S, Godeau E; International HBSC Network Coordinating Committee. The Health Behaviour in School-aged Children: WHO Collaborative Cross-National (HBSC) study: origins, concept, history and development 1982-2008. Int J Public Health. 2009 Sep;54 Suppl 2:131-9

27. Richter M, Erhart M, Vereecken CA, Zambon A, Boyce W, Nic Gabhainn $\mathrm{S}$. The role of behavioural factors in explaining socio-economic differences in adolescent health: a multilevel study in 33 countries. Soc Sci Med. 2009 Aug;69(3):396-403

28. Herrenkohl T, Lee JO, Kosterman R, Hawkins JD. Family influences related to adult substance use and mental health problems: a developmental analysis of child and adolescent predictors. J Adolesc Health. 2012 Aug;51(2):129-35.

29. Morgan AR, Rivera F, Moreno C, Haglund BJ. Does social capital travel? Influences on the life satisfaction of young people living in England and Spain. BMC Public Health. 2012 Feb 12;12:138.

30. Currie C, Nic Gabhainn S, Godeau E, Roberts C, Smith R, Currie D, et al, editors. Inequalities in young people's health: health behaviour in school-aged children international report from the 2005/2006 survey. Copenhagen: WHO Regional Office for Europe; 2008.

31. Roberts C, Freeman J, Samdal O, Schnohr CW, de Looze ME, Nic Gabhainn $\mathrm{S}$, et al; International HBSC study group. The Health Behaviour in School-aged Children (HBSC) study: methodological developments and current tensions. Int J Public Health. 2009 Sep;54 Suppl 2:140-50.

32. Currie C, Roberts C, Morgan A, Smith R, Settertobulte W, Samdal O, et al. Young people's health in context. Health Behaviour in School-aged 
Children (HBSC) study: internatonal report from the 2001/2002 survey. Copenhagen: WHO Regional Office for Europe; 2004.

33. Levin KA, Dallago L, Currie C. The association between adolescent life satisfaction, family structure, family affluence and gender differences in parent - child communication. Soc Indic Res. 2012;106(2):287-305.

34. Siddall J, Huebner ES, Jiang X. A prospective study of differential sources of school-related social support and adolescent global life satisfaction. Am J Orthopsychiatry. 2013 Jan;83(1):107-14.

35. Lyons MD, Huebner ES, Hills KJ, Van Horn ML. Mechanisms of change in adolescent life satisfaction: a longitudinal analysis. J Sch Psychol. 2013 Oct;51(5):587-98.
36. Porubanova-Norquist M. Character as a predictor of life satisfaction in Czech adolescent sample. 3-year follow-up study. Personal Individ Differ. 2012 Aug;53(3):231-5.

Received April 19, 2016 Accepted in revised form March 1, 2017 